\title{
Self-Healing Concrete: Background, Development, and Market Prospects
}

\author{
Pedro Pinto Ferreira Brasileiro 1(D), Yana Batista Brandão ${ }^{2}$ (D), Leonie Asfora Sarubbo ${ }^{3, *(D)}$, Mohand \\ Benachour $^{4}$ (i)
}

1 Departamento de Engenharia Química, Universidade Federal de Pernambuco (UFPE), Av. dos Economistas, s/n, CEP 50740-590, Recife, Brazil; ppfbrasileiro@ hotmail.com (P.P.F.B.);

2 Unidade Acadêmica do Cabo de Santo Agostinho, Universidade Federal Rural de Pernambuco (UFRPE), Cabo de Santo Agostinho, Brazil; yanabatista@yahoo.com.br (Y.B.B.);

3 Centro de Ciências e Tecnologia, Universidade Católica de Pernambuco (UNICAP), Rua do Príncipe, 526, CEP 50050900, Recife, Brazil and Instituto Avançado de Tecnologia e Inovação (IATI), Rua Potyra, 31, CEP 50751-310, Recife, Brazil; leonie.sarubbo@unicap.br (L.A.S.);

4 Departamento de Engenharia Química, Universidade Federal de Pernambuco (UFPE), Av. dos Economistas, s/n, CEP 50740-590, Recife, Brazil; mbena@ ufpe.br (M.B.);

* Correspondence: leonie.sarubbo@unicap.br;

Received: 28.01.2021; Revised: 8.03.2021; Accepted: 12.03.2021; Published: 31.03.2021

\begin{abstract}
The effects of weathering and human activities cause the breakdown of porous structures, such as concrete. Studies have been conducted to address this situation involving the development of self-healing processes that can be employed to seal cracks in concretes in an eco-sustainable manner. This paper addresses the composition and technical norms of concrete, chemical and biological (especially bacteria of the genus Bacillus) healing agents, microencapsulation technologies, calcium carbonate biomineralization processes in concrete, the relation between solubility curves and the crystallization process, crystallization mechanisms and methods, microscopic and macroscopic techniques employed for the characterization of self-healing concrete, and state of the art in periodicals and patents. All these topics are essential to establishing planning for the synthesis and/or characterization of self-healing concretes and reductions in the consumption of cement and production of $\mathrm{CO}_{2}$.
\end{abstract}

Keywords: healing agents; Bacillus; calcium carbonate; solubility curves; crystallization.

(C) 2021 by the authors. This article is an open-access article distributed under the terms and conditions of the Creative Commons Attribution (CC BY) license (https://creativecommons.org/licenses/by/4.0/).

\section{Introduction}

One of the hallmarks of urbanization is the mass production of buildings, avenues, bridges, viaducts, and a gamut of constructions that serve as tools to facilitate daily living. However, one of the challenges is the natural formation of cracks in these buildings due to weathering, resulting in drastic and even fatal situations for whoever lives in urban centers. To address this issue, researchers have studied the development of concrete with the capacity for self-healing, mainly with biotechnology's assistance [1].

Ordinary concrete is composed of cement and water as binding agents and a fine and coarse aggregate to ensure rigidity. Cement has various compositions (although it is difficult to find all classifications in the marketplace) and is the most widely consumed mixture globally due to the large quantity of construction projects. Understanding the production and different classifications of cement is key to the establishment of remediating measures. One of the major 
problems is the toxicity caused by particulate matter containing silicon dioxide $\left(\mathrm{SiO}_{2}\right)$. Therefore, the duality of the high consumption and high toxicity of cement needs to be reconciled [2].

The hydration and drying of cement mixed with fine and coarse aggregate in adequate proportions enable durable concrete formation. However, the effects of weather and human actions cause internal and external cracks in concretes, which require remediating measures. Microorganisms (bacteria and fungi) have been used to adsorb to the interstices of concrete, react with substances such as organic calcium salts, and synthesize compounds such as calcium carbonate to promote the self-healing of cracks in concrete. This phenomenon, known as biomineralization, is found in oysters, as the presence of a parasite in the shell's interior leads to the formation of a pearl [3].

Among the diverse compounds and reactional mechanisms for the self-healing of concrete, calcium lactate is an organic salt that can generate the biomineralization of $\mathrm{CaCO}_{3}$ with greater safety, as metabolic pathways through other compounds, such as urea and nitrogen compounds, induce the synthesis of nitric acid, which causes corrosion in structures with reinforced concrete [4].

The crystallization of material is also an important aspect in bioconcrete systems for controlling and filling pores. This operation, which is the inverse of solubilization, requires knowledge of the following: the solubility curve of substances (linear or exponential; forward or backward); the temperature for a microbial agent to be used in optimal crystallization conditions; possible polymorphs or pseudo-polymorphs of substances, which affect properties such as strength, solubility, and biological interactions; as well as other advantages [5].

By synthesizing calcium carbonate, microorganisms create crystal structures that fill in pores and cracks resulting from natural and anthropogenic phenomena. The microscopic properties of these crystals can be evaluated using scanning electron microscopy and x-ray diffractometry. Macroscopic evaluations of essential characteristics for synthesizing new types of bioconcrete include the determination of compression, tensile, and flexion strength, setting time, expansibility, and paste consistency, as well as thermogravimetric analysis [6].

The present review addresses these topics, underscoring the importance of biotechnology for the construction of eco-sustainable cities and roads, reducing the synthesis of $\mathrm{CO}_{2}$ resulting from the mass production of cement, and reducing the exposure of construction workers to the toxic $\mathrm{SiO}_{2}$ component.

\section{Composition of Concrete}

Concrete has four basic components: water, cement, fine aggregate, and coarse aggregate (Figure 1). The first two are the most widely used compounds in the world and reflect the binding characteristic of concrete, whereas fine and coarse aggregate are incorporated to enhance the rigidity of the material, with variations found in the shape and proportion of the granules [7].

According to Shanks et al. [8], approximately four billion tons of cement are produced per year, which corresponds to the use of $560 \mathrm{~kg}$ per person per year. Along with water, this component is essential to the concrete matrix due to the formation of a cement paste to adhere to the components. The cohesion between water and cement is such that hydraulic cement is the term used to denominate all cement that reacts with water and subsequently hardens. 


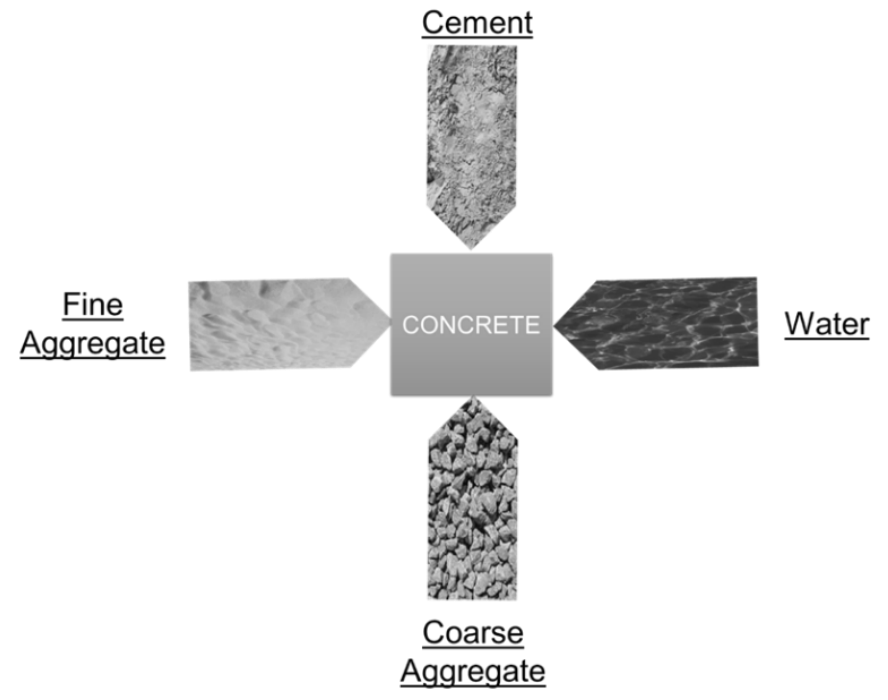

Figure 1. Composition of concrete: cement, water, fine aggregate, and coarse aggregate.

\subsection{Cement.}

The production of cement as a binding agent begins in a limestone mine. Points of the mine are studied to identify possible locations for the mineral extraction using characterization methods, such as scanning electron microscopy (SEM) and x-ray diffractometry (XRD). These techniques assist in the comparison of the material analyzed to standard crystal profiles. When the material exhibits high similarity with the established standards, the limestone is extracted through explosions in the mine until the rocks are small enough to be transported to a nearby factory on large conveyor belts. A second sampling of the material may be performed in the factory to evaluate whether the mineral has similar quality as that found during the initial SEM and XRD analysis and avoid working with inadequate material. After the mineral's effective extraction, the rocks are stored in silos to be mixed with iron ore and clay (aluminum, iron, and magnesium silicates) and ground into a "flour". The proportion of flour varies depending on the type of cement, as different compositions enable different applications. The flour then goes through a preheating phase denominated pre-calcination, in which heat is applied at a temperature of around $1000^{\circ} \mathrm{C}$, which is a little higher than the temperature needed for the breakdown of $\mathrm{CaCO}_{3}$ into $\mathrm{CaO}$ and $\mathrm{CO}_{2}$. Some of the different types of clay are refractory materials that can tolerate temperatures of more than $1500^{\circ} \mathrm{C}$ and can vitrify at around $1300^{\circ} \mathrm{C}$. After the major elimination of the gases during pre-calcination, the flour is submitted to heating between 1000 and $1450^{\circ} \mathrm{C}$ in a continuous rotary kiln, enabling the formation of a mixture denominated clinker. As preheating and heating are the cement industry's main processes, the equipment's maintenance is only performed a few times a year [9].

One of the major environmental problems associated with these types of kilns is the high production of $\mathrm{CO}_{2}$, accounting for 5 to $7 \%$ of global carbon emissions. The consumption of electrical power alone accounts for $10 \%$ of the $\mathrm{CO}_{2}$ emissions from a cement production process. After the vitrification of the clinker, cooling to room temperature occurs. The entire process is illustrated in Figure 2. These data show that cement fabrication causes an increase in greenhouse gases due to both the reactional process and energy needs [8]. 


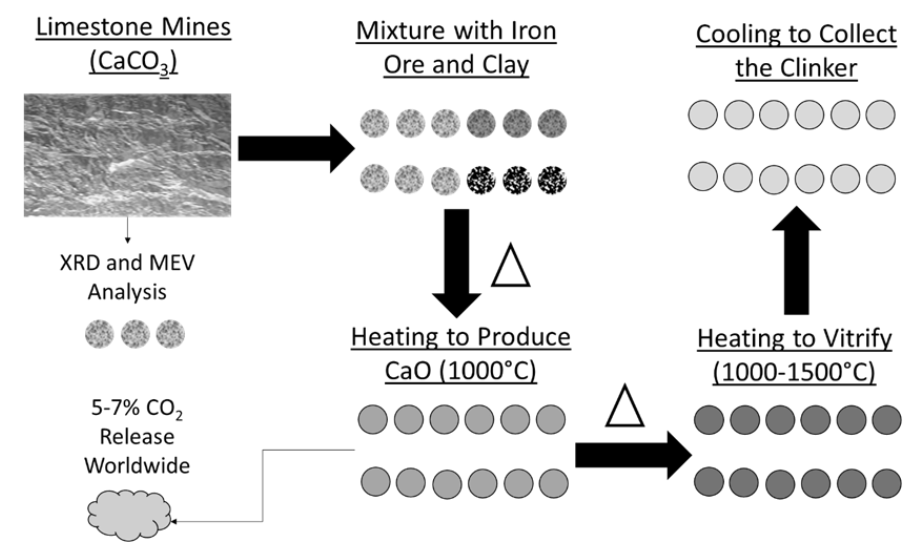

Figure 2. Schematic of clinker production.

After leaving the kiln, the clinker is mixed with different materials: plaster (mainly composed of $\left.\mathrm{CaSO}_{4}\right)$, which is responsible for the setting time of cement; slag $\left(\mathrm{SiO}_{2}\right.$ with other oxides), which is a byproduct of the metal industry; unheated limestone $\left(\mathrm{CaCO}_{3}\right)$ powder as a low-cost, sustainable alternative for the industry; pozzolan (rich in silicates), which is highly resistant to corrosion in conditions of high alkalinity; and filler $\left(\mathrm{CaCO}_{3}\right)$, which is a fine powder to enhance the workability of cement. Figure 3 lists the materials that form traditional cement. Thus, cement composition includes different types of oxides, especially $\mathrm{SiO}_{2}$, anions such as carbonate and sulfate, and cations such as calcium, magnesium, iron, and aluminum [7].

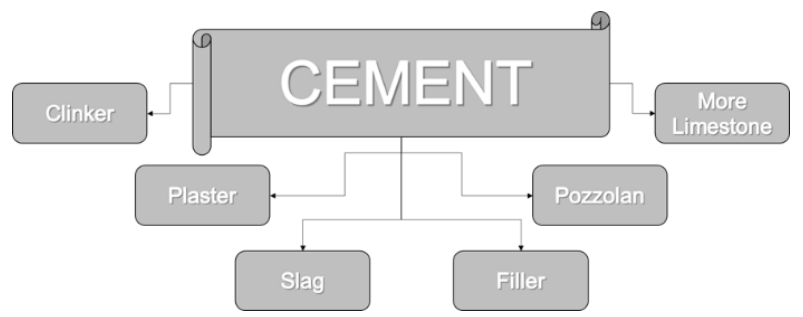

Figure 3. Traditional components of a cement.

The fabrication process is usually directed at the production of Portland cement, which takes its name from the British Isles of Portland. In Brazil, technical norm NBR 16697 unites a set of old norms that specified Portland cement types' composition, describing codes for this specification (Figure 4).

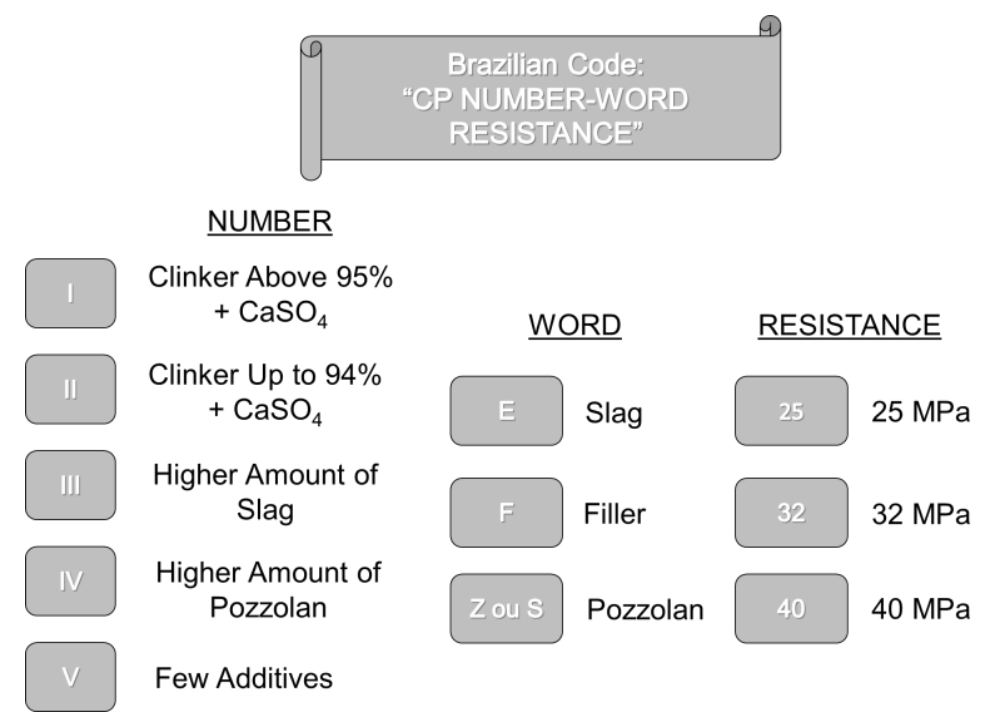

Figure 4. Schematic of brazilian codes for cement production. 
The codes are divided into four parts: a) "CP", which designates the type of cement as Portland; b) type based on composition, such as type I (ordinary), II (compound), III (a blast furnace), IV (pozzolanic) and V (high initial strength); c) additives to the base composition, such as $\mathrm{E}$ (blast furnace slag), $\mathrm{F}$ (filler) and $\mathrm{Z}$ or $\mathrm{S}$ (pozzolanic material); and d) resistance in megapascal (MPa) after 28 days when submitted to a minimum compression of 25, 32 or 40 MPa. Thus, CP II-Z 32 means Portland cement composed of pozzolanic material and resistant to a minimum compression of $32 \mathrm{MPa}$. Subtypes of cement have specific characteristics, as listed below [10]:

- Ordinary cement (CP I): a mixture of at least 95\% clinker with one or more calcium sulfate forms (plaster). This cement type is used to slow the setting time and has a variation of pozzolanic additives (CP I-S) to diminish permeability and corrosion.

- Compound cement (CP II): a maximum mixture of clinker with calcium sulfates of up to $94 \%$, with variations in $\mathrm{E}, \mathrm{F}$, and $\mathrm{Z}$ to have less heat release, greater workability due to the fine filler powder and reduced permeability, respectively.

- Blast furnace cement (CP III): used in works requiring greater strength, such as sewers and dams, with a large amount of slag (silicates).

- Pozzolanic cement (CP IV): greater amount of pozzolans to reduce corrosion and permeability.

- Initial high-strength cement (CP V): practically no additives, with rare exceptions, ensuring greater initial strength on the first day.

\subsection{Fine and coarse aggregates.}

Fine and coarse aggregates, which are usually sand and gravel, respectively, account for $75 \%$ or more of the mass of concrete. Aggregate is an essential factor due to its mechanical and thermal qualities, which influence the concrete's performance, despite not being chemically reactive. The fine aggregate has particles smaller than $4 \mathrm{~mm}$, and the coarse aggregate has particles larger than $5 \mathrm{~mm}$. Grain size is of the utmost importance to the determination of aggregates, as it determines the shape in which the granules can be arranged, affecting characteristics such as porosity, density, and strength. These and other petrographic properties stem mainly from the matrix rock characteristics from which the aggregates were fragmented. Regarding fine aggregate, sand has dimensions between 60 and $70 \mu \mathrm{m}$; the granulometry of silt is between 2 and $60 \mu \mathrm{m}$, and clay has smaller dimensions. Gravel is frequently used as coarse aggregate and may be basalt, limestone, gneiss, or granite [2].

The different proportions of cement (C), fine aggregate (FA), and coarse aggregate (CA) determine the trait of the concrete, which can be represented as C:FA:CA". Thus, a trait of 1:2:3 in mass means that the concrete is one part cement, two parts fine aggregate, and three parts coarse aggregate.

According to Brazilian technical norm NBR 7214, sand used for concrete must be $\geq$ 95\% silica. Considering the previous example with CP III cement (high concentration of silicates), more than half the concrete would be $\mathrm{SiO}_{2}[11]$.

\subsection{Water.}

The universal solvent is of the utmost importance in concrete, as it reacts with the cement and causes the hardening of the concrete. Water is so important to the composition of concrete that there is a water/cement ratio, which is the mass of water's division by the mass of 
cement used [12]. Small water content in the mixture with cement can reduce the concrete setting time but does not ensure high stability or the ultimate performance that can be achieved. In contrast, high water content increases the setting time and can weaken the concrete [12].

\subsection{Types of concrete.}

Composed of the two most widely consumed materials globally, concrete has a wide variety of applications and consequently a gamut of types. The following are the main types $[2,9,13]$ :

- Conventional: ordinary concrete used in construction.

- Pumpable: used with a higher water/cement ratio when transport via a pump is required.

- Reinforced: conventional concrete in which steel bars are embedded to enhance the mechanical strength but have a greater tendency toward corrosion.

- Prestressed: similar to reinforced concrete, this concrete has spaces designed for the insertion of steel cables, also ensuring greater mechanical strength.

- Sprayed (shotcrete): concrete sprayed through a hose using compressed air.

- Light-weight: concrete with a low specific mass, indicated for finishes.

- Heavy: concrete with a high specific mass designed to avoid radiation.

- Cellular: concrete with a foam additive used in dividing walls.

- Self-healing: concrete that can regenerate itself after suffering cracks.

\section{Self-Healing Concretes}

The first investigations on self-healing concrete emerged around 1836. In 1956, crystal formation with $\mathrm{CaCO}_{3}$ was identified. In 1998, researchers were able to recuperate approximately $200 \mu \mathrm{m}$ of a crack using this type of autogenous cure, considerable advancement in chemical studies on self-healing concrete. This process has the following quality parameters: 1) effective sealing of the crack; 2) compatibility of the formed material with the concrete matrix; 3) long-term strength; 4) multiple improvements in the concrete matrix, and 5) sustainable viability. All these characteristics are fundamental to obtaining concrete with excellent healing capacity. The self-healing of concrete can occur in autogenic and autonomous modes. The autogenic mode regards the cement components' hydration, reacting to form calcium carbonate and, subsequently, filling microcracks in the concrete. This hydration process normally occurs at a $\mathrm{pH}$ higher than 7.5. The autonomous mode is strategic selfregeneration that may occur through vascularized systems that enable the percolation of a fluid containing a compound for self-regeneration or a microencapsulation system that releases a compound for self-regeneration the appropriate moment $[4,14]$.

\subsection{Healing agents.}

Healing agents may be polymeric, inorganic, or biological. The application depends on technological and financial availability. Dicyclopentadiene and methyl methacrylate are examples of polymeric agents. Sodium silicate and magnesium oxide are examples of inorganic agents, whereas bacteria (especially those of the genus Bacillus) and fungi are biological agents. Polymeric and inorganic agents have the disadvantage of reacting chemically in a broad temperature and $\mathrm{pH}$ range. These broad ranges are considered disadvantageous because an energy controller is required to stop the chemical reaction. In contrast, bacteria of the genus 
Bacillus have an optimum neutral-alkaline $\mathrm{pH}$ and exhibit metabolic activity within a narrow temperature range, which varies depending on the species [14].

\subsection{Microencapsulation.}

Microencapsulation technology works according to the lab-on-a-chip maxim, which is portability for executing a set of functions, in which two phases exist - one dispersed and one continuous. The first phase is where the healing agent (polymeric, biological, or inorganic) is inserted. The second phase is the surrounding reactive capsule responsible for protecting the healing agent, enabling control over the instant in which the capsule is broken, and the selfhealing process is initiated [15].

There are two main microencapsulation methods: microfluid droplet generation and cross-linking (Figure 5). The first method works basically with capillary hydraulic systems, such as T-junction, flow focusing, and concurrent flow systems. The input pressures of the system enable the micro-encompassing of the dispersed phase the continuous phase [15].

The second method is the densification of the continuous phase on the dispersed phase. The continuous liquid phase begins to gel until the occurrence of the protection of the dispersed phase. This method is subdivided into thermal systems, with polymers of different critical solution temperatures; ionic systems, involving the application of sodium alginate for the gelling of the dispersed phase; and photoinduced systems, involving the application of ultraviolet radiation to photoinitiators enveloped by a photomask [16].

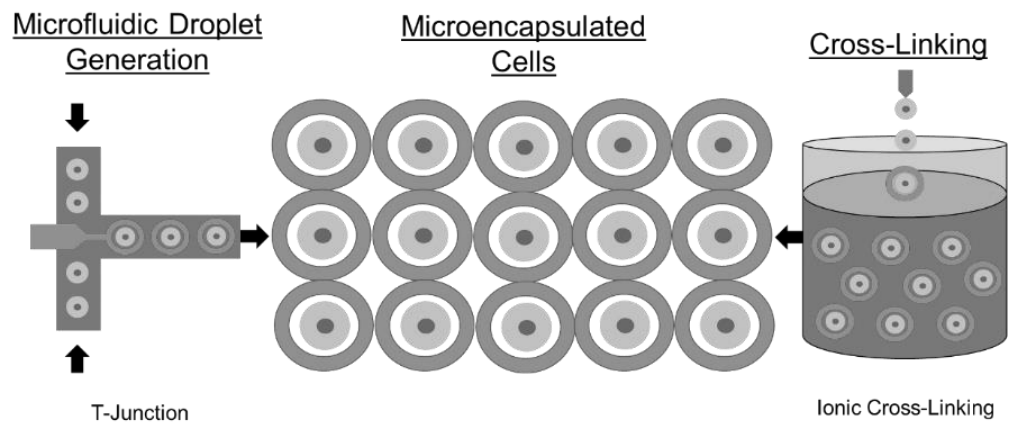

Figure 5. Cellular microencapsulation processes - microfluid droplet generation and cross-linking.

Ionic systems have achieved considerable success in the medical field by integrating 3D printing to create a small vascularized heart through the deposition of cells with sodium alginate in a calcium chloride solution [17].

\subsection{Biomineralization.}

Some organisms have the capacity for biomineralization, which is transforming organic compounds into inorganic compounds followed by the precipitation of the material. The material can then be employed for a specific purpose. Examples of this phenomenon include the formation of mollusk shells for protection from predators' attacks, the production of a pearl in an oyster as a natural reaction to a parasite's presence, and the precipitation of gold or carbonate by bacteria in a nutritive medium [18].

The bacterial precipitation of calcium carbonate has been studied as an option for the reconstitution of concrete. A bacterium consumes the anion of a dissociated calcium organic salt present in the cement and synthesizes the carbonate anion. This new anion is combined 
with the calcium cation, forming biomineralized calcium carbonate and reconstituting the concrete's flaws [19].

The pathways for the biomineralization of calcium carbonate by microorganisms and the self-healing of concrete stem basically from three types of chemical reaction: ureolytic, calcium lactate, and denitrifying pathways [4].

The ureolytic pathway consists of the initial transformation of urea into carbonic acid, according to Equations 1 and 2:

$$
\begin{aligned}
& \mathrm{CO}\left(\mathrm{NH}_{2}\right)_{2}+\mathrm{H}_{2} \mathrm{O} \rightarrow \mathrm{NH}_{2} \mathrm{COOH}+\mathrm{NH}_{3} \\
& \mathrm{NH}_{2} \mathrm{COOH}+\mathrm{H}_{2} \mathrm{O} \rightarrow \mathrm{NH}_{3}+\mathrm{H}_{2} \mathrm{CO}_{3}
\end{aligned}
$$

In equilibrium, hydroxyl and carbonate axions are formed, leading to an increase in $\mathrm{pH}$, according to Equations 3, 4, and 5:

$$
\begin{aligned}
& \mathrm{H}_{2} \mathrm{CO}_{3} \rightarrow \mathrm{HCO}_{3}{ }^{-}+\mathrm{H}^{+} \\
& 2 \mathrm{NH}_{3}+2 \mathrm{H}_{2} \mathrm{O} \rightarrow 2 \mathrm{NH}_{4}^{+}+2 \mathrm{OH}^{-} \\
& \mathrm{CO}_{3}{ }^{2-}+\mathrm{H}^{+}+2 \mathrm{NH}_{4}{ }^{+}+2 \mathrm{OH}^{-} \leftrightarrow \mathrm{CO}_{3}{ }^{2-}+2 \mathrm{NH}_{4}{ }^{+}+2 \mathrm{H}_{2} \mathrm{O}
\end{aligned}
$$

The major problem with the ureolytic pathway is the transformation of ammonium into nitrogen monoxide, causing environmental pollution, albeit at a lower level compared to common sources of pollution. This pathway can also convert ammonium into nitric acid, thereby increasing the possibility of corrosion.

The calcium lactate pathway (Figure 6) is safer and simpler. This pathway consists of the aerobic oxidation of calcium lactate and combination with calcium hydroxide for the synthesis of calcium carbonate, according to Equations 6 and 7:

$$
\begin{aligned}
& \mathrm{CaC}_{6} \mathrm{H}_{10} \mathrm{O}_{6}+6 \mathrm{O}_{2} \rightarrow \mathrm{CaCO}_{3}+5 \mathrm{CO}_{2}+5 \mathrm{H}_{2} \mathrm{O} \\
& 5 \mathrm{CO}_{2}+5 \mathrm{Ca}(\mathrm{OH})_{2} \rightarrow 5 \mathrm{CaCO}_{3}+5 \mathrm{H}_{2} \mathrm{O}
\end{aligned}
$$

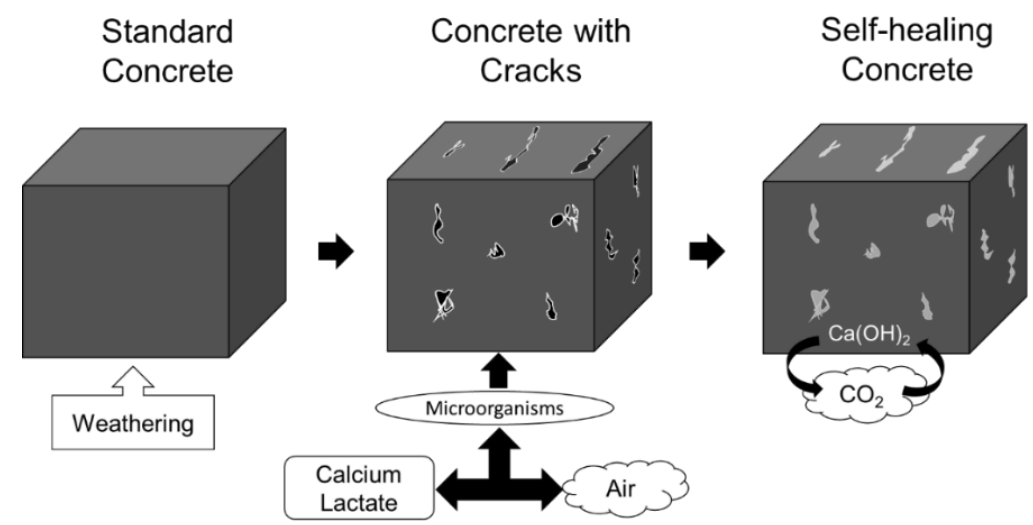

Figure 6. Biomineralization of calcium carbonate by calcium lactate pathway.

The denitrification pathway involves the reduction of nitrate into nitrogen gas and the consequent combination of the formed carbonate with calcium ions, according to Equations 8, 9, and 10:

Organic compound $+a\left(\mathrm{NO}_{3}{ }^{-}\right)+b\left(\mathrm{H}^{+}\right) \rightarrow c\left(\mathrm{CO}_{2}\right)+d\left(\mathrm{H}_{2} \mathrm{O}\right)+e\left(\mathrm{~N}_{2}\right)$

$\mathrm{CO}_{2}+2 \mathrm{OH}^{-} \rightarrow \mathrm{CO}_{3}{ }^{2-}+\mathrm{H}_{2} \mathrm{O}$

$\mathrm{Ca}^{2+}+\mathrm{CO}_{3}^{2-} \rightarrow \mathrm{CaCO}_{3}$ 
The hydrolysis of urea is the fastest path for the production of calcium carbonate, but the fastest path is not always the most adequate, considering the problems above related to corrosion and pollution. Likewise, the denitrification pathway increases the possibility of the transformation of nitrate into nitric acid, accelerating reinforced concrete's corrosion. A similarity in the three pathways is the attraction of calcium cations due to the bacterial surface's negative electrical charge [4].

\section{Solubility Curves And Crystallization}

When placed into a pure solvent, a salt molecule is dissociated into a cation and anion due to intermolecular interactions between the solvent and salt (solute) (Figure 7). As more salt molecules are added to the solvent, more ions are formed until reaching a threshold beyond which the remaining molecules of the solvent no longer have the energy necessary to break the intramolecular bonds of the salt, resulting in the precipitation of the excess salt. Hence, each saline solution has a necessary chemical potential to dissociate the salt occurs [20].

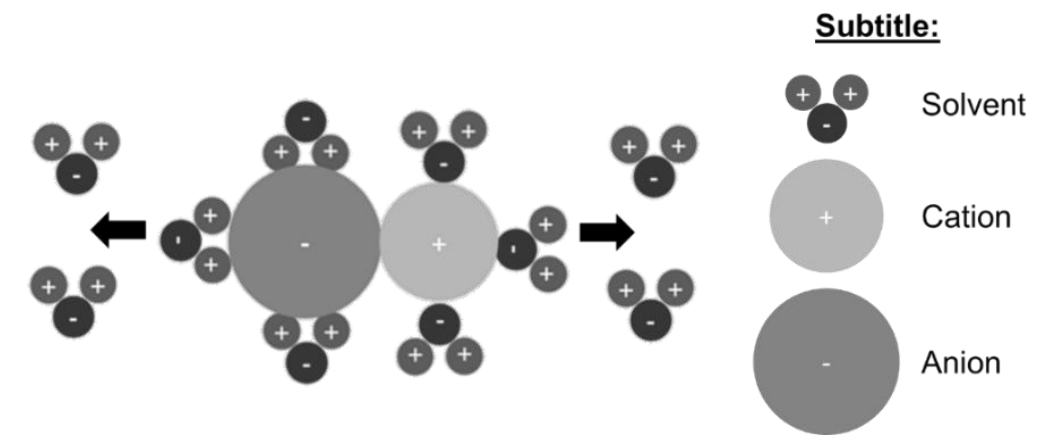

Figure 7. Separation of ions of solute by solvent through intermolecular interactions.

In practice, rather than using chemical potentials, a quantity (in mass) of a given salt is used for a quantity (in volume) of solvent. The salt's solubility limits differ depending on variations in the solute, solvent, pressure, and temperature. Under a single pressure, these limits are graphically represented as a solubility curve comprising the ratio between the quantity (in mass) of a given solute per 100 units (in volume) of the solvent, varying with temperature. Solubility curves can have profiles with linear or exponential variations and with solubility directly (more frequent) or inversely (rarer) proportional to the variation in temperature. The International Union of Pure and Applied Chemistry (IUPAC) offers a set of more than 100 volumes with solubility tables and curves to help researchers find the most adequate, most reliable solubility for solutions. The solubility curve assists in making the ideal choice to enable the recovery of the solute and/or solvent through an operation denominated crystallization, which is the inverse of solubilization and enables the formation of ordered arrangements of molecules in a repetitive matrix (crystals) [20, 21].

The importance of solubility curves to crystallization is exemplified in Figure 8, which displays the solubility curve and metastable limit for any solute and solvent. Below the solubility curve is the unsaturation zone, where the maximum stable degree of dissolution of a component has not yet been reached. Above the solubility curve is a region denominated the supersaturation zone, where the solvent can accommodate a larger quantity of the solute than the limit established by the solubility curve, but in an unstable manner, through a difference in chemical potentials at a fixed temperature. The supersaturation zone is subdivided into a metastable zone and a labile zone through the metastable limit. If linear or with a decreasing 
exponential function, this solubility curve profile will completely change the metastable limit profile and, consequently, change the mechanisms and methods for the occurrence of crystallization [22].

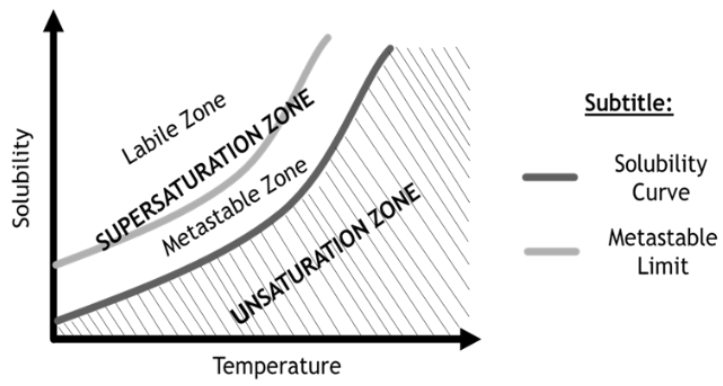

Figure 8. Representation of unsaturation and supersaturation zones with solubility curve and a metastable limit for any solute and solvent.

When the binary mixture (solute and solvent) is in the labile zone, there is extreme instability in the degree of dissolution of this component, and any collision, such as small particulate matter, is sufficient to induce crystallization through a mechanism known as nucleation. A practical example is when water vapor changes from a gaseous state into a solidstate through inverse sublimation or resublimation when striking grains of dust in the air, giving rise to hexagonal snowflakes [22].

In nucleation (Figure 9), as some ions dissolved in the solvent (growth units) in the labile zone perform intermolecular interactions, an unstable entity is formed denominated a cluster. This cluster is unstable because it can break apart again depending on the energy conditions. However, if the cluster keeps growing until reaching a critical size, there is the formation of a stable entity (nucleus). The addition of ions to the nucleus has denominated a crystal. This nucleation mechanism is primary because the nucleus is formed by developing a single cluster but can be secondary with the agglomeration of distinct clusters. Another mechanism of crystallization is crystal growth. This occurs when the formed nuclei are in the metastable region and increase in size with ions' adsorption due to the continued energy instability (difference in chemical potentials) [5, 23].

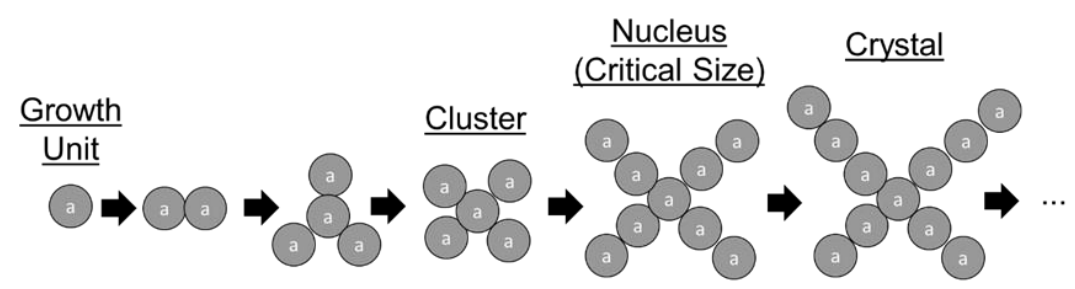

Figure 9. Theory of primary nucleation of a crystal.

A substance may have one or more forms of molecule arrangements upon crystallizing and therefore may present a polymorphism. This phenomenon occurs because it is common in nature for equilibrium to be reached with lower energy consumption, considering the environment in which the solute and solvent are found. In an industrial process, polymorphs can be formed under different operating conditions, such as variations in temperature and pressure (altering the mechanical, physiochemical, and thermal properties), as well as biological interactions. Ammonium nitrate is often used as a fertilizer, but the two nitrogen atoms in this molecule have a variation in the oxidation number between -3 and +5 , which are the minimum and maximum oxidative states permitted for the nitrogen group in the periodic table. In the presence of heat, an auto-redox reaction abruptly releases a quantity of energy, 
characterizing an explosion. Thus, the polymorphism can transform a fertilizer substance into an explosive [24].

As an example of a physicochemical property, solubility is strongly influenced by the morphology of the crystal. Therefore, a substance can have different solubilities depending on the polymorphism. More stable polymorphs have less solubility. For crystals' obtainment in cooling and heating processes, water molecules can adhere to the molecules of the crystal, forming inclusions, but these hydrated compounds are not the same isolated molecules and are therefore denominated pseudo polymorphs [5].

Calcium carbonate can exhibit three distinct crystalline forms and has a reverse solubility curve (solubility diminishes with the increase in temperature). At a fixed temperature and pressure, the crystalline forms (in increasing order of solubility) are calcite (found in limestone mines), aragonite (found in karstic caverns and the exoskeletons of animals), and vaterite (found in gall stones and kidney stones). Due to its lower solubility, calcite is the most stable and most common form of calcium carbonate crystallization [25].

Methods for the crystallization of compounds vary depending on the solubility curve. Crystals can be formed in the following ways: I) cooling, when the solubility of the solute is directly proportional to temperature, avoiding the use of heat exchangers and the occurrence of fouling; II) evaporation as occurs in saline for the production of $\mathrm{NaCl}$, when the solute varies little with the change in temperature; III) melting, when a solid contains two or more substances and the separation of one is needed through distinct points of fusion; IV) precipitation by an antisolvent, in which the solubility of a solute is reduced with the formation of a mixed solvent; $\mathrm{V})$ precipitation by a chemical reaction, in which the synthesis of a product with low solubility occurs; and other methods [5].

In the case of the precipitation of calcium carbonate induced by microorganisms, the concreate or solidified cement exhibits porous fractures that can be filled with solutions containing lactate and/or microorganisms or microbial spores and/or gaseous systems containing air or $\mathrm{O}_{2}$. This triphasic system has two main phenomena: biochemical reactions and crystallization, depending on each crystallizing model. The measurement of the reaction and crystallization rates results in the limiting velocity of the process, enabling knowledge of the conditions necessary for the control of the process, especially in synthesizing the three polymorphs of $\mathrm{CaCO}_{3}$. Bacteria of the genus Bacillus have the advantage of having a negatively charged cell wall, which attractions $\mathrm{Ca}^{2+}$ cations or undissolved calcium lactate molecules. When this complex adheres to the surface with crystalline nuclei formation, the crystallization of calcium carbonate occurs through biomineralization [26].

Some microorganisms used in the crystallization process also have the biotechnological potential for the synthesis of natural surfactants (biosurfactants), which can assist in the selfhealing of concrete through the use of bacteria and fungi, as the biosurfactants enable the microorganisms to penetrate the pores of the concrete with greater ease by lowering the surface tension. Biosurfactants promote an increase in the humectation (capillarity) of the fluid, facilitating the penetration of bacteria and fungi into the narrower pores of the concrete, and promote the crystallization of microcracks; the low toxicity of these natural surfactants also ensures the viability of the microorganisms [27]. Durval et al. [28] confirmed the low toxicity of biosurfactants produced by Bacillus cereus strain. Thus, microorganisms can serve as both healing agents and producers of biosurfactants to improve the crystallization process. 


\section{Characterization of Self-Healing Concrete}

The entire process has standardized quality parameters to ensure reproducibility and determine possible continual improvement and the consequent development of the procedure from the artisanal realm to the technoscientific realm. The biomineralization of calcium carbonate in concrete through the calcium lactate pathway can be characterized using assays addressing the cement and concrete's macroscopic properties and the microscopic properties of the product formed by the healing agent in the concrete matrix. The following are analyses of the macroscopic properties of cement that can be performed:

a) Normal paste consistency: technique stipulated in Brazil by technical norm NBR 16606 regarding the penetration depth of a probe into cement paste; the Vicat apparatus is used for this analysis [29].

b) Setting time: technique stipulated in Brazil by technical norm NBR 16607 regarding the hardening of a cement paste; the Vicat apparatus is also used for this analysis [30].

c) Expansibility: technique stipulated in Brazil by technical norm NBR 11582 indicating the variation in cement volume. High expansibility is normally not required due to the rigid cement paste's possible rupture; the Le Chatelier apparatus is used for this analysis [31].

The addition of fine and coarse aggregate enables analyzing the macroscopic properties of concrete. Cylindrical or prismatic molds are needed for experiments with test specimens, following Brazilian technical norm NBR 5738:2015, 2016 revised version [32]. The following are examples of concrete strength tests [2]:

a) Simple compression: a test of the reduction in volume in the presence of two opposing axial forces.

b) Simple tensile: a test of the increase in volume in the presence of two opposing axial forces.

c) Flexion: test in the presence of a force orthogonally applied to the center of mass of the test specimen.

Other macroscopic tests include the following:

a) Permeability: capacity of concrete to retain a liquid, generally water [33].

b) Thermogravimetric analysis (TGA): method in which a solid is heated at a particular constant rate until reaching a particular temperature for the determination of the loss of mass and degree of degradation [34].

Tests of microscopic properties are also important to identify what probable components are being studied and determining the petrographic characteristics of a material. The following methods can be used for studying bioconcrete [6, 34]:

(a) Scanning electron microscopy (SEM): the use of three-dimensional topographic profiles to examine the material's crystallinity; SEM is not a complete quantitative measure due to the different types of images but is a widely employed tool for the visualization of microscopic abnormalities

(b) X-ray diffraction (XRD): a crystallographic technique in which a known x-ray beam is applied to a sample at a particular angle, causing diffraction of the beam. The standard deviation of the rays corresponds to the variation in electron density in the crystal, enabling the determination of a crystallographic profile and identifying possible constituents.

SEM responses are data that can be interpreted through the comparison of photographs. In contrast, XRD requires comparing crystallographic profiles found in databanks with distinct profiles from different world regions. HighScore Plus ${ }^{\circledR}$ from PANalytical B.V.C is one of the 
software programs used for profile analysis, enabling the importation of the crystallographic profile obtained from a diffractometer, the comparison of the profile to an integrated data bank, listing possible compatibilities with the diffractogram and compatibility percentages, and the editing of the probable components for the material in question. Therefore, this software program is an essential tool for XRD analysis [35].

\section{Patents of Self-Healing Concrete and Similar Systems}

For a company, the registration of intellectual property regards an intangible product of the human mind. Patents protect the ideas of inventors, and an investigation of patent records reveals the market aspects of different types of processes [36].

Regarding self-healing concretes, methods and inventions are found in the Netherlands, the USA, South Korea, China, and Japan. Thus, a large portion of such patents is found in Asia.

Song et al. [37] proposed a system in series to recycle solutions containing healing agents in concrete cylinders partitioned axially. The aim was to compare the solid medium's permeability and the healing agent's sealing potential, as a less permeable medium would denote greater self-regeneration. In this system, a solution percolates through a cylinder and promotes the concrete's self-healing in accordance with the level of pressure of the solution in the cylinder.

Shin et al. [38] devised sealing not by immersion in a solution but through a diffusion process of gases applied orthogonally to a concrete block. The test specimen had a crack through which the gases could penetrate and promote the concrete regeneration process. Concrete blocks can be bio-regenerated by the sealing mechanism with calcium lactation through the concrete's oxygen gas diffusion.

Jonkers [39] report that some genera of bacteria are preferable for the self-healing of concretes, such as Planococcus, Bacillus, and Sporosarcina, especially Bacillus. In this patent, the inventor indicates mass ratios between 1) the bacterial material and healing agent in the range of 1:10000 to 1:1000000, with the cellular material dry and in well-divided proportions, and 2) the healing agent and cement in the range of 1:20 to 1:2000, preferably 1:50 to 1:500 (including water).

Wiktor and Jonkers [40] proposed a method for conditioning concrete to bacterial action for self-healing through a mixture of two liquids: a healing agent and a gelling agent. This mixture promotes the self-healing of concrete, mainly on inclined surfaces or ceilings, where the weight force of a more fluid liquid impedes it from staying in place. For example, sodium silicate (gelling agent) and a calcium salt (healing agent), such as calcium nitrate, could be used. The authors suggest applying the healing agent 30 minutes after the application of the gelling agent.

Li et al. [41] suggest implementing concrete containing calcium lactate salts and perlite granules to protect basophilic organisms, such as Bacillus cereus, from unfavorable environmental conditions. According to the inventors, Bacillus cereus in the dormant state in a dry environment can remain viable for up to 50 years.

Keung et al. [42] created a method for forming microcapsules with the capacity to promote the self-healing of concrete. This development involved the initial mixture of surfactants (polyethylene glycol dioleate, sorbitan laurate, polyethylene glycol isostearate, and others), healing agents (such as colloidal silica), and encapsulating polymers (such as polyurethane and polystyrene). The mixture was homogenized at a low, stirring speed (50 to $600 \mathrm{rpm}$ ) for the formation of an emulsion and then at high speed (1000 to $12000 \mathrm{rpm}$ ) in the 
presence of catalysts, such as bismuth carboxylate, zinc carboxylate, and mercaptide oxides. The change in speed was necessary for the initial emulsification and the consequent formation of larger silica droplets. The high stirring speeds in the emulsification process reduced the colloidal silica droplets' size, causing phase separation.

\section{Self-Healing Concretes and Similar Systems in Periodicals}

Reddy et al. [43] address a set of chemical healing agents, such as crystalline mixtures, polymers, and fibers, for concrete self-healing. The authors also report the thickness of crystalline recovery and the type of exposure to environmental conditions (dry or wet).

Reddy et al. [44] offer an excellent compilation of four types of bacteria of the genus Bacillus (megaterium, pasteurii, sphaericus, and subtilis) from diverse bibliographic sources for application in self-healing concrete, indicating where the bacteria are found, cell concentration ranges in the medium, the common working temperature for the bacteria, and the encapsulation material. The authors also compare the strength of the concrete considering different bacterial concentrations.

Martuscelli et al. [45] evaluated the biotechnological potential of 19 species of fungi grown in Petri dishes with a urea medium $(20 \mathrm{~g} / \mathrm{L})$ for six days, identifying strains of Cladosporium herbarum, Cladosporium angustiherbarum, and Penicillium brevicompactum as having ureolytic activity based on the strong change in color.

Rauf et al. [46] submitted sporulated strains of Bacillus subtilis, Bacillus cohnii, and Bacillus sphaericus to different media containing urea (0.0 to $2.8 \%, \mathrm{~m} / \mathrm{m}$ of cement) and calcium lactate $(1.2$ to $4.0 \%, \mathrm{~m} / \mathrm{m}$ of cement) for 28 days. The authors evaluated the thickness of the concrete seal, diffractograms of the self-healed concretes, and compression strength, reporting the following results: the maximum thickness of $0.8 \mathrm{~mm}$; diffractograms containing calcite and aragonite as polymorphs of calcium carbonate; and maximum compression strength of $42 \mathrm{MPa}$. B. sphaericus demonstrated the best efficiency regarding the recovery of concrete.

Zhang et al. [3] pre-inoculated a strain of Bacillus cohnii and two microorganism colonies under anoxic and anaerobic conditions in a medium containing calcium lactate $(8 \mathrm{~g} / \mathrm{L})$. The solutions were placed in devices for the simultaneous testing of the concrete's permeability and its regeneration by $\mathrm{CaCO}_{3}$ in 28-day experiments. XRD analysis was also performed. The researchers found maximum calcification of $1.22 \mathrm{~mm}$ under anoxic conditions of the colonies after the study period. Moreover, permeability in water presence was reduced by incorporating calcium salts into the concrete structure. Under these conditions, calcite and aragonite (both crystals of $\mathrm{CaCO}_{3}$ ) were found in the diffractograms.

Brasileiro et al. [47] added calcium lactate (2.8 to $6.6 \%$, w/w of cement) to the composition of cement, hydrating and solidifying the mixture in $15-\mathrm{cm}$ Petri dishes, followed immediately by the inoculation of $1 \mathrm{~mL}$ of a medium containing Bacillus cereus (107 cells $/ \mathrm{mL}$ ). The authors observed crystal growth on the cement's surface (Figure 10) for seven days and performed XRD analysis. The two main results were nucleations formed after about $17 \mathrm{~h}$ and peaks in the sample's diffractogram, revealing an initial $6.6 \%$ calcium lactate, corresponding to $82 \% \mathrm{SiO}_{2}$ and $18 \% \mathrm{CaCO}_{3}$ (calcite).

\section{Conclusions}

This paper discussed the main aspects of the synthesis of self-healing concrete, from the initial production of cement to the patenting of solutions. 
Regarding cement production, we identified the main components that need to be addressed in novel methods to replace toxic agents, such as $\mathrm{SiO}_{2}$, and the suggestion of novel reactional and bioreaction mechanisms for the sealing of cracks in traditional concrete. Moreover, it is important to know the technical norms that govern the production process so that all mechanisms are proposed, preferably following such norms or so that a technical norm commission can be formed to effectuate changes.

Regarding microencapsulation technologies, we discussed the types of healing agents and ways to store these agents for future applications and the adequate bioreactional mechanisms for the effective self-healing of concrete over time without weakening the system.

In terms of crystallization, we addressed the importance of knowledge on each substance's solubility curve and each polymorph of each substance, and we point out the existence of pseudo polymorphs. The solubility curve of a substance enables testing the adequate crystallization methods for a process and adapting novel crystallization methods to the microorganism, type of cement, and bioreaction process.

In evaluating self-healing concrete properties, we identified the routine methods used for both macroscopic and microscopic analyses to indicate competitiveness with traditional concrete production processes.

One of the challenges of biotechnology is its incorporation into traditional production processes in the industry to achieve improvements in the process, such as optimizing the properties of a material and/or a reduction in the toxicity of compounds employed in the process. Meeting this challenge requires an adequate theoretical basis encompassing market aspects through records of intellectual property and scientific aspects found in international periodicals and books. Therefore, the production of self-healing concrete is a challenge to be met with biotechnology.

\section{Funding}

This research was funded by Postgraduate Program in Chemical Engineering of the Center for Technology and Geosciences of the Universidade Federal de Pernambuco (UFPE), the Brazilian fostering agency Coordenação de Aperfeiçoamento de Pessoal de Nível Superior (CAPES (Coordination for the Advancement of Higher Education Personnel - Finance Code 001), Instituto Avançado de Tecnologia e Inovação (IATI [Advanced Institute of Technology and Innovation]) and Universidade Católica de Pernambuco (UNICAP).

\section{Acknowledgments}

The authors are grateful to the Postgraduate Program in Chemical Engineering of the Center for Technology and Geosciences of the Universidade Federal de Pernambuco (UFPE), the Brazilian fostering agency Coordenação de Aperfeiçoamento de Pessoal de Nível Superior (CAPES (Coordination for the Advancement of Higher Education Personnel), Instituto Avançado de Tecnologia e Inovação (IATI [Advanced Institute of Technology and Innovation]) and Universidade Católica de Pernambuco (UNICAP) for the financial, technical, academic, and scientific resources.

\section{Conflicts of Interest}

The authors declare no conflict of interest. 


\section{References}

1. Nain, N.; Surabhi, R.; Yathish, N.V.; Krishnamurthy, V.; Deepa, T.; Tharannum, S. Enhancement in strength parameters of concrete by application of Bacillus bacteria. Constr. Build. Mater. 2019, 202, 904-908, https://doi.org/10.1016/j.conbuildmat.2019.01.059.

2. Neville, A.M. Propriedades do Concreto. 5th ed. Bookman: Porto Alegre, Brazil, 2016.

3. Zhang, J.; Zhao, C.; Zhou, A.; Yang, C.; Zao, L.; Li, Z. Aragonite formation induced by open cultures of microbial consortia to heal cracks in concrete: Insights into healing mechanisms and crystal polymorphs. Constr. Build. Mater. 2019, 224, 815-822, https://doi.org/10.1016/j.conbuildmat.2019.07.129.

4. Sidiq, A.; Gravina, R.; Giustozzi, F. Is concrete healing really efficient? A review. Constr. Build. Mater. 2019, 205, 257-273, https://doi.org/10.1016/j.conbuildmat.2019.02.002.

5. Guardani, R.; Seckler, M.M.; Giulietti, M. Cristalização. Purificação De Produtos Biotecnológicos. 2nd ed.; Kilikian, B.V., Pessoa Júnior, A., Eds., Blucher: São Paulo, Brazil, 2020.

6. Mors, R.M.; Jonkers, H.M. Feasibility of lactate derivative based agent as additive for concrete for regain of crack water tightness by bacterial metabolism. Ind. Crop. Prod. 2017, 106, 97-104, https://doi.org/10.1016/j.indcrop.2016.10.037.

7. Brito, J.; Kurda, R. The past and future of sustainable concrete: A critical review and new strategies on cement-based materials. J. Clean. Prod. 2020, 281, 1-72, https://doi.org/10.1016/j.jclepro.2020.123558.

8. Shanks, W.; Dunant, C.F.; Drewniok, M.P.; Lupton, R.C.; Serrenho, A.; Allwood, J.M. How much cement can we do without? Lessons from cement material flows in the UK. Resour. Conserv. Recy. 2019, 141, 441454, https://doi.org/10.1016/j.resconrec.2018.11.002.

9. Singh, G.V.P.B.; Subramaniam, K.V.L. Production and characterization of low-energy Portland composite cement from post-industrial waste. J. Clean. Prod. 2019, 239, https://doi.org/10.1016/j.jclepro.2019.118024.

10. Associação Brasileira De Normas Técnicas. NBR 16697: Cimento Portland - Requisitos. Rio de Janeiro, 2018a; pp. 12.

11. Associação Brasileira De Normas Técnicas. NBR 7214: Areia normal para ensaio de cimento Especificação. Rio de Janeiro, 2015; pp. 4.

12. Hover, K.C. The influence of water on the performance of concrete. Constr. Build. Mater. 2011, 25, 30033013, https://doi.org/10.1016/j.conbuildmat.2011.01.010.

13. Chica, L.; Alzate, A. Cellular concrete review: New trends for application in construction. Constr. Build. Mater. 2019, 200, 637-647, https://doi.org/10.1016/j.conbuildmat.2018.12.136.

14. Danish, A.; Mosaberpanah, M.A.; Salim, M.U. Past and present techniques of self-healing in cementitious materials: A critical review on efficiency of implemented treatments. J. Mater. Res. Technol. 2020, 9, 68836899, https://doi.org/10.1016/j.jmrt.2020.04.053.

15. Kanellopoulos, A.; Giannaros, P.; Palmer, D.; Kerr, A.; Al-Tabbaa, A. Polymeric microcapsules with switchable mechanical properties for self-healing concrete: synthesis, characterisation and proof of concept. Adv. Mater. Res-Switz. 2017, 26, 1-16, http://dx.doi.org/10.1088/1361-665X/aa516c.

16. Alkayyali, T.; Cameron, T.; Haltli, B.; Kerr, R.; Ahmadi, A. Microfluidic and cross-linking methods for encapsulation of living cells and bacteria - A review. Anal. Chim. Acta. 2019, 1053, 1-21, https://doi.org/10.1016/j.aca.2018.12.056.

17. Noor, N.; Shapira, A.; Edri, R.; Gal, I.; Wertheim, L.; Dvir, T. 3D Printing of Personalized Thick and Perfusable Cardiac Patches and Hearts. Adv. Sci. 2019, 6, 1-10, https://doi.org/10.1002/advs.201900344.

18. Bastrzyk, A.; Fiedot-Tobola, M.; Polowczyk, I.; Legawiec, K.; Plaza, G. Effect of a lipopeptide biosurfactant on the precipitation of calcium carbonate. Colloid. Surface. B. 2019, 174, 145-152, https://doi.org/10.1016/j.colsurfb.2018.11.009.

19. Vijay, K.; Murmu, M., Deo, S.V. Bacteria based self healing concrete - A review. Constr. Build. Mater. 2017, 152, 1008-1024, https://doi.org/10.1016/j.conbuildmat.2017.07.040.

20. Genck, W.J.; Albin, B.; Baczek, F.A.; Dickey, D.S.; Gilbert, C.G.; Herrera, T.; Laros, T.J.; Li, W.; Mccurdie, P.; Mcgillicuddy, J.K.; Mcnulty, T.P.; Moyers, C.G.; Schoenbrunn, F.; Wisdom, T.W.; Chen, W. LiquidSolid Operations And Equipment. Perry's Chemical Engineer's Handbook. 9th ed.; Green, D.W. (Eds.), Southard, M.Z.; McGrawHill Education: New York, United States of America, 2019.

21. International Union of Pure and Applied Chemistry (IUPAC), Solubility Data. Series. Available online: https://iupac.org/what-we-do/databases/solubility-data-series/ (Accessed on 13 September 2020).

22. Foust, A.; Wenzel, L.; Clump, C.; Maus, L.; Andersen, L. Princípios das Operações Unitárias, traduction by Horácio Macedo. 2nd ed.; LTC: Rio de Janeiro, Brazil, 2013.

23. Mullin, J.W. Crystallization. 4th ed.; Butterworth-Heinemann: Oxford, England, 2001.

24. Oxley, J.C.; Smith, J.L.; Rogers, E.; Yu, M. Ammonium nitrate: thermal stability and explosivity modifiers. Thermochim. Acta. 2002, 384, 23-45, https://doi.org/10.1016/S0040-6031(01)00775-4.

25. Chen, J.; Xiang, L. Controllable synthesis of calcium carbonate polymorphs at different temperatures. Powder Technol. 2009, 189, 64-69, http://dx.doi.org/10.1016/j.powtec.2008.06.004.

26. Lucas, S.S.; Moxham, C.; Tziviloglou, E.; Jonkers, H. Study of self-healing properties in concrete with bacteria encapsulated in expanded clay. Sci. Technol. Mater. 2018, 30, 93-98, https://doi.org/10.1016/j.stmat.2018.11.006. 
27. Daltin, D. Tensoativos: Química, propriedades e aplicações. 1st ed.; Blucher: São Paulo, Brazil, 2011.

28. Durval, I.J.B.; Mendonça, A.H.R.; Rocha, I.V.; Luna, J.M.; Rufino, R.D.; Converti, A.; Sarubbo, L.A. Production, characterization, evaluation and toxicity assessment of a Bacillus cereus UCP 1615 biosurfactant for marine oil spills bioremediation. Mar. Pollut. Bull. 2020, 157, 1-8, https://doi.org/10.1016/j.marpolbul.2020.111357.

29. Associação Brasileira De Normas Técnicas. NBR 16606: Cimento Portland - Determinação da pasta de consistência normal. Rio de Janeiro, 2018b, pp. 8.

30. Associação Brasileira De Normas Técnicas. NBR 16607: Cimento Portland - Determinação dos tempos de pega. Rio de Janeiro, 2018c; pp. 4.

31. Associação Brasileira De Normas Técnicas. NBR 11582: Cimento Portland - Determinação da expansibilidade Le Chatelier. Rio de Janeiro, 2016a; pp. 4.

32. Associação Brasileira De Normas Técnicas. NBR 5738: Concreto - Procedimento para moldagem e cura de corpos de prova. Rio de Janeiro, 2016b; pp. 9.

33. Mengel, L.; Krauss, H.; Lowke, D. Water transport through cracks in plain and reinforced concrete Influencing factors and open questions. Constr. Build. Mater. 2020, 254, 1-12, https://doi.org/10.1016/j.conbuildmat.2020.118990.

34. Pindelska, E.; Sokal, A.; Kolodziejski, W. Pharmaceutical cocrystals, salts and polymorphs: Advanced characterization techniques. Adv. Drug. Deliver. Rev. 2017, 117, 111-146, https://doi.org/10.1016/j.addr.2017.09.014.

35. Kaur, J.; Tripathi, S.K.; Ankush; Sharma, M.D.; Kanika; Goyal, N. Rietveld Refinement Study of GeSb $\mathrm{Se}_{4}$ Bulks Prepared Through Distinct Melting Profiles. Mater. Today-Proc. 2017, 4, 9524-9528, https://doi.org/10.1016/j.matpr.2017.06.217.

36. Chagas, E.E. Direito Empresarial. 5th ed.; Saraiva Educação: São Paulo, Brazil, 2018.

37. Song, T.; Lee, S.; Park, J. Permeability Test Method and Apparatus for Self Healing Concrete. Depositor: Korea Institute of Construction Technology. KR n $101453312 B 1$. Filled: 14 March 2014. Granted: 22 October 2014.

38. Shin, S.J.; Lee, D.G.; Lim, M.; Lee, G. Gas diffusion test apparatus and test method for test evaluation of crack width and self-healing performance of crack specimen. Depositors: Chungnam National University Industry-Academic Cooperation Foundation; Sungkyunkwan University Industry-Academic Cooperation Foundation. KR n $102105840 B 1$. Filled: 16 November 2018. Granted: 29 April 2020.

39. Jonkers, H.M. Healing agent for self-healing cementious materials. Depositor: Technische Universiteit Delft. NL n 2004520C2. Filled: 07 April 2010. Granted: 11 October 2011.

40. Wiktor, V.A.C.; Jonkers, H.M. Bio-based repair method for concrete. Depositors: Technische Universiteit Delft and Stichting voor de Technische Wetenschappen te Utrecht. NL no 2010818C2. Filled: 17 May 2013. Granted: 24 November 2014.

41. Li, Z.; Zhang, J.; Zhao, L. Crack self-repairing concrete using aerobic and alkaliphilic microorganisms and preparation method thereof. Depositor: Taiyuan University of Technology. $\mathrm{CN} \mathrm{n}^{\mathbf{o}}$ 106045400A. Filled: 03 June 2016. Granted: 09 March 2018.

42. Keung, L.H.; Tan, N.P.B.; Choi, W.H.; Lam, W.C. Self-Healing Material And Preparation Process Thereof. Depositors: Nano and Advanced Materials Institute Limited. US n 9598313B2. Filled: 28 June 2015. Granted: 21 March 2017.

43. Reddy, P.V.Y.; Ramesh, B.; Macrin, D. Effect of crystalline admixtures, polymers and fibers on self healing concrete - a review. Mater. Today-Proc. 2020a, 33, 763-770, https://doi.org/10.1016/j.matpr.2020.06.122.

44. Reddy, P.V.Y.; Ramesh, B.; Kumar, L.P. Influence of bacteria in self healing of concrete - a review. Mater. Today-Proc. 2020b, 33, 4212-4218, https://doi.org/10.1016/j.matpr.2020.07.233.

45. Martuscelli, C.; Soares, C.; Camões, A.; Lima, N. Potential of Fungi for Concrete Repair. Proc. Manuf. 2020, 46, 180-185, https://doi.org/10.1016/j.promfg.2020.03.027.

46. Rauf, M.; Khaliq, W.; Khushnood, R.A.; Ahmed, I. Comparative performance of different bacteria immobilized in natural fibers for self-healing in concrete. Constr. Build. Mater. 2020, 258, 1-13, https://doi.org/10.1016/j.conbuildmat.2020.119578.

47. Brasileiro, P.P.F.; Soares da Silva, R.C.F.; Rocha e Silva, F.C.; Brandão, Y.B.; Sarubbo, L.A.; Benachour, M. Biomineralization of Calcium Carbonate by Bacillus Cereus for Self-healing Biocement. Chem. Engineer. Trans. 2020, 79, 97-102, https://doi.org/10.3303/CET2079017. 